\title{
Pain management in chronic pancreatitis: taming the beast
}

This article was published in the following Dove Press journal:

Clinical and Experimental Gastroenterology

4 September 2013

Number of times this article has been viewed

\section{Chijioke Enweluzo \\ Letlhogonolo Tlhabano}

Section on Hospital Medicine, Department of Internal Medicine, Wake Forest School of Medicine, Winston Salem, NC, USA
Correspondence: Chijioke Enweluzo Section on Hospital Medicine, Department of Internal Medicine, Wake Forest School of Medicine, Ground Floor, Meads Hall, Medical Center Boulevard, Winston Salem, NC, 27I57 USA $\mathrm{Tel}+\mathrm{I} 3367135215$

Email cenweluz@wakehealth.edu
Abstract: Abdominal pain is a principal and in many cases, the only observable symptom of chronic pancreatitis. Like all chronic pain conditions, managing abdominal pain in chronic pancreatitis remains an onerous task for health care providers. Different mechanisms have been postulated in trying to better understand the pathogenesis of pain in chronic pancreatitis. This review seeks to take a broad look at the various options that are available to providers in trying to achieve pain relief and a better quality of life for chronic pancreatitis patients.

Keywords: chronic pancreatitis, pain management

\section{Introduction}

Abdominal pain is a principal and in many cases, the only observable symptom of chronic pancreatitis. It can range from an intermittent, periodical discomfort, especially in the early stages of the disease course, to a more constant debilitating symptom, which is typical of later stages. Pain could occur with or without other symptoms such as nausea, vomiting, and weight loss. Like all chronic pain conditions, managing abdominal pain in chronic pancreatitis remains an onerous task for health care providers. Different mechanisms have been postulated in trying to better understand the pathogenesis of pain in chronic pancreatitis. Pancreatic hyperstimulation, ischemia, and necrosis are some of the more common mechanisms that have been proffered in trying to understand this condition. ${ }^{1}$ Oxidative stresses, obstruction of small and large pancreatic ducts leading to ductal hypertension, and necrosis-fibrosis have also been implicated. ${ }^{2-4}$ Most of these theories indicate long-term alcohol abuse as the central cause/starting point of the disease process. ${ }^{5}$ Smoking has also been identified as a cause of chronic pancreatitis. Alcohol exerts toxic effects on the intracellular metabolism of pancreatic acinar cells, resulting in pancreatic lipid accumulation, fatty breakdown, cellular necrosis, and fibrosis. Alcohol is also said to increase the lithogenicity of pancreatic fluid, resulting in stone formation. Long-term contact between stones and pancreatic epithelial cells can lead to scarring as well as cause an increase in pancreatic duct pressure by blockage of ducts as mentioned earlier. The pancreatic duct possesses poor compliance, so the presence of stones easily results in ductal and tissue hypertension leading to necrosis manifesting as severe abdominal pain. The pancreas is an organ that is richly innervated. Inflammation and damage to the pancreatic nerve is also implicated as a cause of pain in chronic pancreatitis. Studies have shown that operations that remove the head of the pancreas in chronic pancreatitis patients have led to significant improvement in pain, as the head of the gland happens to be the most innervated region. ${ }^{6,7}$ It is our belief 
that a better knowledge of the pathogenesis of pain in this condition will lead to better health outcomes.

\section{Pain management modalities}

Like most chronic pain conditions, pain management in chronic pancreatitis is best achieved if a graded, multidisciplinary approach is followed. General issues that need to be resolved include making sure that the patient quits alcohol and tobacco use. The expertise of an addiction specialist may be helpful to achieve abstinence from alcohol or smoking. Small meals, low in fat and adequate hydration should be encouraged. Supplementation with medium chain triglycerides (MCT) such as found in the enteral formula, Peptamen ${ }^{\circledR}$ (Nestle HealthCare Nutrition, Inc., Florham Park, NJ, USA), has also been shown to be beneficial. Shea et al conducted a prospective study of eight patients with chronic pancreatitis who were placed on three cans per day of the enteral formulation containing MCT and hydrolyzed peptides for 10 weeks. ${ }^{8}$ Baseline pain scores and cholecystokinin (CCK) levels were determined for 2 weeks prior to the onset of the study. At the end, they concluded that an enteral supplement containing MCT and hydrolyzed peptides minimally increased plasma CCK levels. They also noted an improvement in pain scores from baseline.

\section{Pancreatic enzyme supplementation}

Pancreatic enzyme supplements work via a modification of the CCK release feedback mechanism. Typically, the pancreatic enzyme CCK is released from the pancreas for intraduodenal food digestion by CCK releasing factors, which in turn are destroyed by digestive enzyme proteases, creating a negative feedback mechanism. ${ }^{9}$ However in chronic pancreatitis, reduction of intraduodenal free enzyme activity by increased undigested proteins, protease inhibitors, or inadequate pancreatic enzyme secretion allows the CCK releasing factors to survive protease digestion, leading to hyperstimulation of the gland, resulting in a positive feedback mechanism and significant abdominal pain. Pancreatic enzymes are believed to interrupt this positive feedback mechanism and hyperstimulation, resulting in pain relief. Non-enteric and enteric-coated forms of the supplements are available. Presently in the United States, the only Food and Drug Administration (FDA)-approved form is the enteric-coated version. Different studies have been done to verify the efficacy of the supplements with varying results. ${ }^{10-13}$ However, only high doses of the non-enteric versions have been shown to provide pain relief in clinical trials. In cases where non-enteric coated versions are used, acid suppression with a proton pump inhibitor is highly recommended. Clinical experience has shown some benefit in the administration of pancreatic enzyme supplementation. Some studies have suggested that this benefit may be mostly placebo. ${ }^{14,15}$ Nonetheless, pancreatic enzyme supplementation remains an important pain control modality in chronic pancreatitis.

\section{Analgesics}

Analgesics can be non-narcotic or narcotic. ${ }^{10}$ Keeping with the graded approach theme, pain management in early stages can respond adequately to non-narcotic analgesia with drugs such as acetaminophen, especially when combined with the early introduction of pancreatic enzymes. However, from clinical experience, abdominal pain quickly becomes more constant and debilitating. Here, introduction of narcotics is considered appropriate. Drugs such as morphine, hydromorphone, and hydrocodone are commonly used in different formulations. These should be introduced while keeping the World Health Organization analgesic ladder in mind. ${ }^{16}$ Patients with concomitant renal insufficiency may benefit more from fentanyl. If symptoms are exacerbated to the point of requiring hospitalization, keeping the patient nil by mouth for a short period of time may help reduce pancreatic stimulation and hence pain. Like in every chronic pain condition requiring narcotic medication use, chemical dependency is always a concern and this needs to be carefully and frequently examined by the health care provider, especially in patients who may still have addiction issues with alcohol or smoking. A psychiatric evaluation may be necessary to exhaustively assess chemical dependency. Other medications such as nortriptyline and gabapentin may be necessary in providing neuropathic pain, especially if pancreatic nerve involvement is considered. ${ }^{17}$ Use of an acute or chronic pain management service to find the "right" pain regimen for each patient may be necessary. There is no set time or criteria that define when pain management can be upgraded to other more invasive modalities in cases where pain control is not achieved on medications.

\section{Endoscopic ultrasound-guided celiac plexus block}

The celiac plexus is a complex network of nerves located in the abdomen where the celiac trunk, superior mesenteric artery, and renal arteries branch from the abdominal aorta. It is behind the stomach and the omental bursa, and in front of the crura of the diaphragm, on the level of the first lumbar vertebra. It is partly formed by the greater and lesser 
splanchnic nerves of both sides, and also parts of the right vagus nerve. It consists of the celiac ganglia with a network of interconnecting fibers. A celiac plexus block is commonly used in cases of chronic pancreatitis with pain refractory to conservative pain management measures as described above. The block is usually achieved with steroids in chronic pancreatitis cases although ethanol can also be used. The procedure is commonly done via endoscopic ultrasonography (EUS), but can also be carried out percutaneously and surgically. ${ }^{18,19}$ Some studies have suggested marginal benefit with the percutaneous approach compared to the others. ${ }^{19-21}$ The percutaneous approach has also been suggested to provide better and faster short-term relief. ${ }^{20-22}$ Most of these studies are considered to be small, retrospective studies with a considerable amount of subjectivity. Nonetheless, the EUS guided approach has the advantage of better needle localization of the ganglia and adequate spread of the injectate, resulting in better pain relief and fewer complications. Two main approaches are commonly employed endoscopically: an anterior/anterocrural approach in which there is injection anterior to the diaphragm with diffusion of the injectate over the celiac ganglia, while the classic/retrocrural approach leads to diffusion of the injectate over the splanchnic nerves. A commonly used injectate is the steroid triamcinolone. A minimal amount of alcohol can be added to this for its bactericidal properties. In place of alcohol, broad spectrum antibiotics can also be used. EUS-guided celiac plexus block is a relatively safe procedure. Commonly reported complications, which occur rarely, include: transient diarrhea, asymptomatic hypotension, retroperitoneal abscess, and of course post-procedural pain. ${ }^{24}$ Eisenberg et al reported that transient diarrhea and hypotension result from the sympathetic blockade that can occur following celiac plexus block and may be seen in up to $38 \%$ and $44 \%$ of patients, respectively, whether performed by EUS or percutaneous approaches. ${ }^{25}$ Other complications include lower extremity weakness and paresthesias, paraplegia, pneumothorax, renal puncture, and prolonged gastroparesis. ${ }^{26}$ As a whole, neurological complications are most related to a posterior approach. Hayakawa et al from Japan reported a case of paraplegia following intraoperative celiac plexus block. ${ }^{27}$

\section{Endoscopic therapy}

As mentioned before, increase in pancreatic duct pressure/ ductal hypertension has been postulated as one of the mechanisms of abdominal pain in chronic pancreatitis. This ductal hypertension can result from blockage of the pancreatic duct from any cause such as strictures, stones, or Sphincter of Oddi dysfunction. The aim of endoscopic therapy is to achieve decompression of the pancreatic duct leading to resolution of ductal hypertension and hopefully pain resolution. Rösch et al conducted a prospective, multicenter study of over 1,000 patients with painful chronic pancreatitis and identified ductal obstruction due to either strictures and/or stones. ${ }^{28}$ The patients were treated endoscopically at eight different centers and underwent follow-up for between 2-12 years (mean 4.9 years). Of 1,211 patients treated, data was obtained from 1,018 (84\%) during follow-up. Of this number, 47\% had mainly strictures, $18 \%$ mainly stones, and $32 \%$ had both strictures and stones. At the end long-term follow-up, $60 \%$ of the patients had their endotherapy completed, $16 \%$ were still receiving some form of endoscopic treatment, and $24 \%$ had undergone surgery. The long-term success of endotherapy was $86 \%$ in the entire group, but only $65 \%$ in an intention-totreat analysis. They did not report any significant differences between the patient groups with regard to strictures, stones, or both. Pancreatic function was also not positively affected by endoscopic therapy.

\section{Extracorporeal shock wave lithotripsy (ESWL)}

ESWL is employed in the fragmentation of pancreatic duct stones in the hope that the smaller fragments can be easily passed from the pancreatic duct. This is not a commonly used or well-studied modality of pain management. At best, ESWL can be used prior to endoscopic therapy for better outcomes. $^{29}$

\section{Surgery}

This is considered a last option in the treatment of pain in chronic pancreatitis. It is mainly for those who have failed medical or endoscopic therapy. It can also be used to effectively investigate the presence of pancreatic cancer. Surgery follows three options: (1) decompression, (2) resection, and (3) denervation. Obviously, decompression is employed in cases of obstructed pancreatic duct from any cause. Some studies have suggested that surgical forms of decompression may actually be more effective in terms of pain relief in the longer term compared to endoscopic therapy. ${ }^{29,30}$ As stated before, resection of part of the pancreatic gland (head or tail, but not the whole gland) usually leads to pain relief. Resection is considered in patients who have failed other forms of therapy or those who are not candidates for a drainage procedure (usually patients with predominantly small duct disease). This may result in exocrine and endocrine dysfunction, as these patients may not have enough remaining 
functioning pancreatic reserve considering their history of chronic pancreatitis..$^{6,731,32}$ Denervation can be achieved using an open surgical approach or using thoracoscopic surgery/ bilateral thoracoscopic splanchnicectomy. ${ }^{33,34}$ The aim is to interrupt the rich nerve supply from the celiac ganglia and splanchnic nerves. Further study is required into this form of surgical therapy.

\section{Radiation}

This is an emerging modality in the treatment of pain in chronic pancreatitis patients. Guarner et al, in a prospective study of 15 consecutive patients who were treated with single dose radiotherapy for painful chronic pancreatitis, found that during follow-up (median: 39 months; range: 4-72 months), 12 patients had no further pain or flare-ups. ${ }^{35}$ One patient required a second radiation dose 1 year after the initial treatment, but remained well since then (50 months at the time of reporting). Two other patients did not respond to radiotherapy. After radiotherapy, either exocrine or endocrine pancreatic function, or both, deteriorated in three patients. They concluded that radiotherapy for severe symptomatic chronic pancreatitis appears to be a useful and effective therapeutic choice that could potentially substitute for or delay surgery. Further research into this area is needed.

\section{Conclusion}

As a whole, chronic pancreatitis is a condition that is not yet fully understood. What remains clear is that therapy for pain needs to be individualized by understanding the possible pathogenesis at play for each patient. After that is achieved, a graded, multidisciplinary approach is most beneficial.

\section{Disclosure}

The authors report no conflicts of interest in this work.

\section{References}

1. Bradley EL 3rd. Pancreatic duct pressure in chronic pancreatitis. Am J Surg. 1982;144(3):313-316.

2. Bhardwaj P, Garg PK, Maulik SK, Saraya A, Tandon RK, Acharya SK. A randomized controlled trial of antioxidant supplementation for pain relief in patients with chronic pancreatitis. Gastroenterology. 2009;136(1):149-159. e2.

3. Karanjia ND, Widdison AL, Leung FW, et al. Blood flow alterations in chronic pancreatitis: Effects of secretory stimulation (abstract). Gastroenterology. 1990;98:A221.

4. Karanjia ND, Singh SM, Widdison AL, Lutrin FJ, Reber HA. Pancreatic ductal and interstitial pressures in cats with chronic pancreatitis. Dig Dis Sci. 1992;37(2):268-273.

5. Coté GA, Yadav D, Slivka A, et al; North American Pancreatitis Study Group. Alcohol and smoking as risk factors in an epidemiology study of patients with chronic pancreatitis. Clin Gastroenterol Hepatol. 2011;9(3): 266-273; quiz e27.
6. Ahmed Ali U, Pahlplatz JM, Nealon WH, van Goor H, Gooszen HG, Boermeester MA. Endoscopic or surgical intervention for painful obstructive chronic pancreatitis. Cochrane Database Syst Rev. 2012;1: CD007884.

7. Díte P, Ruzicka M, Zboril V, Novotný I. A prospective, randomized trial comparing endoscopic and surgical therapy for chronic pancreatitis. Endoscopy. 2003;35(7):553-558.

8. Shea JC, Bishop MD, Parker EM, Gelrud A, Freedman SD. An enteral therapy containing medium-chain triglycerides and hydrolyzed peptides reduces postprandial pain associated with chronic pancreatitis. Pancreatology. 2003;3(1):36-40.

9. Owyang C. Negative feedback control of exocrine pancreatic secretion: role of cholecystokinin and cholinergic pathway. J Nutr. 1994;124(Suppl 8):1321S-1326S.

10. Singh VV, Toskes PP. Medical therapy for chronic pancreatitis pain. Curr Gastroenterol Rep. 2003;5(2):110-116.

11. Isaksson G, Ihse I. Pain reduction by an oral pancreatic enzyme preparation in chronic pancreatitis. Dig Dis Sci. 1983;28(2):97-102.

12. Halgreen H, Pedersen NT, Worning H. Symptomatic effect of pancreatic enzyme therapy in patients with chronic pancreatitis. Scand J Gastroenterol. 1986;21(1):104-108.

13. Mössner J, Secknus R, Meyer J, Niederau C, Adler G. Treatment of pain with pancreatic extracts in chronic pancreatitis: results of a prospective placebo-controlled multicenter trial. Digestion. 1992;53(1-2): 54-66.

14. Malesci A, Gaia E, Fioretta A, et al. No effect of long-term treatment with pancreatic extract on recurrent abdominal pain in patients with chronic pancreatitis. Scand J Gastroenterol. 1995;30(4):392-398.

15. Brown A, Hughes M, Tenner S, Banks PA. Does pancreatic enzyme supplementation reduce pain in patients with chronic pancreatitis: a meta-analysis. Am J Gastroenterol. 1997;92(11):2032-2035.

16. World Health Organization. WHO analgesic pain ladder. Available from: www.who.int/cancer/palliative/painladder/en/. Accessed May 25, 2013.

17. Gilron I, Bailey JM, Tu D, et al. Nortriptyline and gabapentin, alone and in combination for neuropathic pain: a double-blind, randomised controlled crossover trial. Lancet. 2009;374(9697):1252-1261.

18. Wang PJ, Shang MY, Qian Z, Shao CW, Wang JH, Zhao XH. CT-guided percutaneous neurolytic celiac plexus block technique. Abdom Imaging. 2006;31(6):710-718.

19. Carroll I. Celiac plexus block for visceral pain. Curr Pain Headache Rep. 2006;10(1):20-25.

20. Sahai AV, Lemelin V, Lam E, Paquin SC. Central vs bilateral endoscopic ultrasound-guided celiac plexus block or neurolysis: a comparative study of short-term effectiveness. Am J Gastroenterol. 2009;104(2): 326-329.

21. Gress F, Schmitt C, Sherman S, Ikenberry S, Lehman G. A prospective randomized comparison of endoscopic ultrasound- and computed tomography-guided celiac plexus block for managing chronic pancreatitis pain. Am J Gastroenterol. 1999;94(4):900-905.

22. Gress F, Schmitt C, Sherman S, Ciaccia D, Ikenberry S, Lehman G. Endoscopic ultrasound-guided celiac plexus block for managing abdominal pain associated with chronic pancreatitis: a prospective single center experience. Am J Gastroenterol. 2001;96(2):409-416.

23. Wiersema MJ, Wiersema LM. Endosonography-guided celiac plexus neurolysis. Gastrointest Endosc. 1996;44(6):656-662.

24. O'Toole TM, Schmulewitz N. Complication rates of EUS-guided celiac plexus blockade and neurolysis: results of a large case series. Endoscopy. 2009;41(7):593-597.

25. Eisenberg E, Carr DB, Chalmers TC. Neurolytic celiac plexus block for treatment of cancer pain: a meta-analysis. Anesth Analg. 1995;80(2): 290-295.

26. Mercadante S, Nicosia F. Celiac plexus block: a reappraisal. Reg Anesth Pain Med. 1998;23(1):37-48.

27. Hayakawa J, Kobayashi O, Murayama H. Paraplegia after intraoperative celiac plexus block. Anesth Analg. 1997;84(2):447-448. 
28. Rösch T, Daniel S, Scholz M, et al; European Society of Gastrointestinal Endoscopy Research Group. Endoscopic treatment of chronic pancreatitis: a multicenter study of 1000 patients with long-term follow-up. Endoscopy. 2002;34(10):765-771.

29. Parsi MA, Stevens T, Lopez R, Vargo JJ. Extracorporeal shock wave lithotripsy for prevention of recurrent pancreatitis caused by obstructive pancreatic stones. Pancreas. 2010;39(2):153-155.

30. Strate T, Bachmann K, Busch P, et al. Resection vs drainage in treatment of chronic pancreatitis: long-term results of a randomized trial. Gastroenterology. 2008;134(5):1406-1411.

31. Gall FP, Gebhardt C, Meister R, Zirngibl H, Schneider MU. Severe chronic cephalic pancreatitis: use of partial duodenopancreatectomy with occlusion of the pancreatic duct in 289 patients. World J Surg. 1989;13(6):809-816; discussion 816-817.
32. Martin RF, Rossi RL, Leslie KA. Long-term results of pyloruspreserving pancreatoduodenectomy for chronic pancreatitis. Arch Surg. 1996;131(3):247-252.

33. Buscher HC, Jansen JB, van Dongen R, Bleichrodt RP, van Goor H. Long-term results of bilateral thoracoscopic splanchnicectomy in patients with chronic pancreatitis. Br J Surg. 2002;89(2):158-162.

34. Maher JW, Johlin FC, Heitshusen D. Long-term follow-up of thoracoscopic splanchnicectomy for chronic pancreatitis pain. Surg Endosc. 2001;15(7):706-709.

35. Guarner L, Navalpotro B, Molero X, Giralt J, Malagelada JR. Management of painful chronic pancreatitis with single-dose radiotherapy. Am J Gastroenterol. 2009;104(2):349-355.

\section{Publish your work in this journal}

Clinical and Experimental Gastroenterology is an international, peerreviewed, open access journal, publishing all aspects of gastroenterology in the clinic and laboratory, including: Pathology, pathophysiology of gastrointestinal disease; Investigation and treatment of gastointes tinal disease; Pharmacology of drugs used in the alimentary tract;
Immunology/genetics/genomics related to gastrointestinal disease. This journal is indexed on CAS. The manuscript management system is completely online and includes a very quick and fair peer-review system. Visit http://www.dovepress.com/testimonials.php to read real quotes from published authors.

Submit your manuscript here: http://www.dovepress.com/clinical-and-experimental-gastroenterology-journal 